\title{
Pas de deux for Dancer and Camera in Maya Deren's Films
}

\author{
Sarah Keller
}

A n expansive interest in dance guided Maya Deren's ambitions even before she began to make films. She served as secretary for progressive choreographer and research anthropologist Katherine Dunham's dance troupe in 1942, touring with their production of the musical Cabin in the Sky. That same year, she published an article on religious possession and dance in the American journal Educational Dance. She was fond of dancing both formally and informally: friends recall her dancing at the slightest provocation. Then, in her first films, including Meshes of the Afternoon (1943) and At Land (1944), Deren embraced "dancerly" movement as one of several ways of producing meaning outside of narrative paradigms.' By the time she made A Study in Choreography for Camera (1945), her relationship to dance-film was solidified. Then and thereafter, she consistently collaborated with trained dancers and talented choreographers (Talley Beatty, Rita Christiani, Frank Westbrook, Anthony Tudor, Jean Erdman) over several film projects. Further, she participated in lectures and discussions on film and dance, and she published articles in venues such as Dance magazine, articulating her aims for using dance in her films. She began to categorize several of her films as "choreographies for camera,"2 compared their form to dance forms, and reflected at length on how the two media could be combined towards the goal of a wholly new artistic expression. Her investment in dance, as a filmmaker, was impressive and sustained across her career.

Deren invented a unique aesthetic for filmed dance that drew on her own theories of cinema; on current trends in modern dance, the art world, and anthropology; and on the example of several cinematic predecessors. In his recent book Screendance: Inscribing the Ephemeral Image (2012), Douglas Rosenberg outlines some of the artistic debts owed by Deren's expression of a relationship between camera and dancer, noting that her work belongs to a "continuum of production that flows from a rhizomatic network of sources,"3 including Eadweard Muybridge's early photographic motion studies as well as the "particular type of physicality" in performers such as Charlie Chaplin and Buster Keaton. ${ }^{4}$ Further, he notes the influence of modernist artists such as Marcel Duchamp and Man Ray, who were experimenting with the effects of movement in their work - work which came to include the cinema. ${ }^{5}$ Indeed, it is certain that a wide range of artists, including Loïe Fuller, Fernand Léger, René Clair, and Germaine Dulac, are indisputable forerunners to what Deren developed as a film-dance aesthetic, more or less directly. For instance, Dulac's abstract film Thèmes et variations (1928) combines the movements of a dancer with parallel movements in nature and machinery, predating Deren's similar use of dancers within her mise-en-scène; likewise the slow motion of the funeral procession in Clair's Entr'Acte (1924) predicts Deren's own investigations into how the manipulation of film time creates rhythms within otherwise mundane events. Deren experimented with combining cinematic movement and 
dance movement in ways that are indebted to such artists, and even as she forged her own aesthetic, it developed with strong parallels to their earlier work. ${ }^{6}$

Deren's investment in dance expanded her sense of the purview of cinema; her notion of cinematic specificity, for example, came as a result of using cinematic devices to connect with the rhythms of dance in her films. In this way, she extended the reach of modern dance's coincident trend to include natural movements (e.g., following the later developments championed by the Judson Church dancers ${ }^{7}$ ) by showing how such movements performed in compelling combination with cinematic movements might augment both media according to their special features. ${ }^{8}$ For example, in the movement of Deren's hair at the end of the first sequence in Ritual in Transfigured Time (1946), Deren manipulates temporality in a slow-motion study to make time unfold in an unfamiliar way. Correspondingly, the sequence initiates a compelling, dance-like rhythm. In Deren's longest and most complex statement of film theory, An Anagram of Ideas on Art, Form, and Film, published that same year, she describes her reasons for shooting an action (shaking one's hair) in this fashion:

When a fast turning is reduced by slow-motion, it still looks natural, and merely as if it were being performed more slowly; the hair, however, moving slowly in the lifted, horizontal shape possible only to rapid tempos, is unnatural in quality. Thus one creates a movement in one tempo which has the qualities of a movement of another tempo, and it is the dynamics of the relationship between these qualities which creates a certain special effectiveness, a reality which can only be achieved through the temporal manipulation of natural elements by the camera as an art instrument. ${ }^{9}$

Deren attempts the kind of shot she describes here first in her climb up a ladder of driftwood in At Land, ${ }^{10}$ but such an effort gains complexity as it unfolds in Ritual in Transfigured Time. In this later film, Deren appears, turning her head in slow motion while she vivaciously talks and winds yarn with the character played by Rita Christiani (one of Katherine Dunham's dancers). As Deren suggests in her writings, the slow motion of this moment affords the spectator the ability to analyze the subtlest intricacies of the figure's movement: intricacies inaccessible to the unassisted eye. The way the yarn moves, the nuances of Deren's facial expression, and the broader gestures of her bodily movement are broken down into an entirely new rhythm, which is revealed more potently in the slower motion effected by the camera. We see the fast, graceful, "dancerly" movements of the actor (as filmed) intersected by the slow motion of the camera, making a new rhythm of the two in partnership.

Moreover, the slow-motion movement underlines options available to the cinematic medium for expressing a rhythmic sense of time. The shots are cut between Rita Christiani and Deren winding the yarn into a ball together, and Anaïs Nin standing in the threshold of a doorway beyond. First, the film depicts Christiani turning her head in "real" time, at a regular, unhurried pace. In slight slow motion, Nin turns her head to look away from the women. The image of turning, shared by these three women across several shots, communicates the shifting relationships among them (at first Christiani seems to feel welcomed by Deren, then alienated as Deren disappears within the space of Christiani turning towards her). The rhythm of this simple gesture is played out in several different temporal registers: we have someone turning quickly but depicted slowly via camera time; we have someone turning slowly in both camera and real time; and we have three people turning individually 
at a normal speed in real time but slowed or extended by the way Deren draws that collective turn across several shots. By cutting to close-ups of the yarn or to a longer shot of the three women in a line, Deren further attenuates the action of turning and contextualizes it in an activity (creating the ball of yarn, women gathering in a room). The fugue of rhythms binds their activity together and underlines the feeling of how time passes via these multiple indications of cinematic temporality.

There are several ways that Ritual in Transfigured Time explores rhythm according to cinematic modes. For instance, it underlines a specifically cinematic rhythm in its sequence that takes place among statues, where it freezes certain frames to highlight cinema's dependence upon and simultaneous ability to manipulate a relationship between stasis and motion. The fact of making the dancing figures like statues also evokes a metaphorical relationship, asserting kinship between the mobile figures and the statues among which they frolic. Rhythm, deriving from alternation from stasis into motion, underlies the nature of the cinematic medium: twenty-four still frames per second allowing for the illusion of collective movement of those frames (and the images depicted in them). Such rhythmical relationships in fact drove Deren's investment in dance as cinematic subject and film-theoretical touchstone, which has corollaries in several of her passions beyond filmmaking, including fine arts, anthropology, and poetry. She was an incorrigible touch-à-tout, who tried her hand at many things, perhaps partly to find the best avenue for expressing her ideas. As a result, she refined and honed her film practice cross-medially. Deren drew important conclusions about film art based on issues she explored through dance and poetry in particular, in that both depend on a sense of rhythm that Deren derived from these models and expressed in vertiginous spatial and ideational mobility within and between the frames of her films.

Deren displayed an active interest in poetic form from an early age. This interest developed in important ways throughout her short filmmaking career, and is most resonant in her treatment of dance on film. Poetry, rhythm and dance serve as keys for understanding the primacy of temporal investigation and reinvention in her films. As her first artistic outlet, poetry exerted an especially powerful influence on both Deren's conceptual thinking and her filmic conceits. From early amateur versifying for her school journal, where she first received encouragement for her poems (she wrote home from boarding school in Switzerland, "I am hailed by all the girls as a sure poet"11), until soon after she met her second husband Alexander Hammid and began to make films, Deren identified as a poet, claiming it as her artistic calling. ${ }^{12}$ Hammid later described the genesis of Meshes, on which they collaborated in 1943, as deriving from Deren's poetic sensibility combined with his own cinematic expertise. He recalls that she was at that time "writing poetry always. It was one of her main ambitions. So she started with poetic images on paper, and I was visualizing them."13 Their work together charted a movement from imagination to image through rhythms determined both by movement within the frame and through editing, where those rhythms were dictated equally by the duration of shots, slow or fast motion, and spatial relationships among a set of images. This trajectory, from imagination to image through rhythm, shaped Deren's later work more broadly.

Poetic precedents in her films are evident in the way Deren addressed questions of temporality and rhythm. In fact, she mobilized several modes of poetic thinking in her film work: she used poetry as a metaphor for cinema itself, enlisted visual metaphors to express ideas, theorized a "poetic" temporality as preferable for cinema (the "horizontal" and 
"vertical" thesis Deren posited in greatest detail in 1953, at a symposium on poetry and film organized by Cinema 16 ${ }^{14}$ ), and described the nature of the "image" in cinema in terms that resonate with her work on Imagist poets prepared for her master's thesis at Smith College. Focused on the Symbolists and the Imagists, and exploring how each group resolved the dilemma of how images generate poetic ideas, Deren's thesis culminated in a chapter on Ezra Pound and T.S. Eliot. Pound's pronouncements about the directness of the image-e.g. "that which presents an intellectual and emotional complex in an instant of time" - were refashioned in Deren's thinking according to the technical specificities of the film camera. ${ }^{15}$

To convey her sense of the directness of expression that she posited was more readily available to the visual image (she claimed poetic ideas could not convey images so directly, in that they had to capitulate to the intermediary mechanism of language ${ }^{16}$ ), Deren found a perfect vehicle in the gestural, charged expressivity of dance. For Deren's aesthetic, cinematic dance is most immediate and capable of conveying ideas, emotions, and rhythms with directness and force. She put the resources of her background in poetry and her exposure to dance to work in the moving image, offering an artistic method in contradistinction to literary and theatrical linearity, chronology, and causality. Doing so, she importantly reconfigured the temporal relationships within the artwork: her work favors models that allow development according to recursions of time characteristic of memory, dreams, and rituals. Deren's films accrue meaning based on the non-linear juxtaposition of related actions and images, expressed both directly and indirectly through the paradigms of poetry and dance.

A Study in Choreography for Camera (1945), the third film Deren completed, succinctly illustrates these influences. A brief film of barely three minutes duration, Study was conceived by Deren as an equal partnership between the dancer and the camera: a pas de deux. It progresses over four very short sequences, and features just one dancer, Talley Beatty. He begins in a birch forest, moves to a living room and then to the Egyptian Hall at the Metropolitan Museum before returning to the out-of-doors for the last part of the piece. His body connects these disparate spaces, beginning a gesture in one setting and completing it in another, making use of a standard device in continuity editing (a match on action) for holding together a somewhat jarring discontinuity. Dance, rhythm, and poetic devices provide virtually the entirety of the form and content for this film.

The opening section of Study articulates one of several metaphorical relationships introduced by the film. It implicates man (Beatty) and nature (trees) by filming them both as part of the natural movement within the setting. In his book Film at Wit's End, filmmaker Stan Brakhage describes the cooperation between the film's mise-en-scène and Beatty's movements, which "rhyme with all the little branches of the trees around him. So that he is a rhyme with the trees. In fact, during the first pan across, he can almost be missed as being a tree."17 On the level of the mise-en-scène, Beatty's figure functions as if he were part of the background; his body generates a sense of symmetry by being a graphic match within the frame. Deren fashions the image so that Beatty mirrors his surroundings, implying a relationship between natural movement (branches in wind) and creative movement within the film (the dancer among those branches), as well as outside of the film (through the movement of the camera).

The third section more fully elaborates such relationships. It begins with another match on action, shifting the scene without warning from Beatty's spin in a living room area to a 


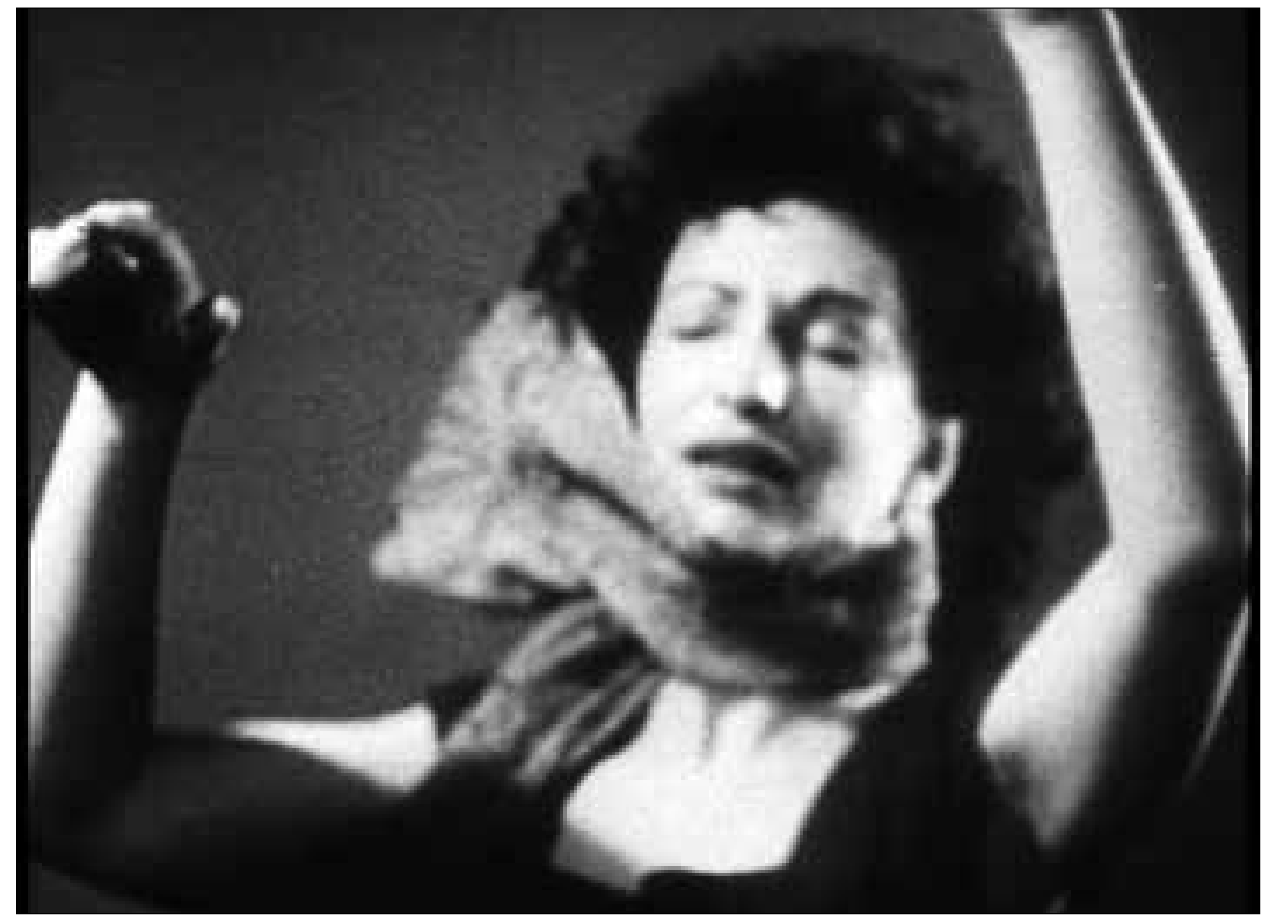

Fig. 1: A study of motion and rhythm in Ritual in Transfigured Time (Maya Deren, 1946).

shot of his legs completing that spin on a new surface. He runs gracefully away from the camera in what is revealed to be (as the camera tilts up) a long gallery. ${ }^{18}$ When he reaches the end of the room, he turns and retraces his steps, returning to a position closer to the camera and the same framing of his legs. Deren masks the spatial discontinuity by beginning with a close view without contextualizing details, so we don't immediately know he is in a place other than where he began. ${ }^{19}$ The new space is further made strange, disjunctive, by Deren's use of a wide-angle lens, making the hall appear much longer than it actually is. This exaggerated perspective, as Deren asserts, "by causing him to diminish in size very rapidly, makes it seem as if he had covered a tremendous distance in a relatively short time."20 The camera assists in conveying the rhythm of the dance, but with new parameters specific to its own devices and capacities.

The close-up of Beatty's feet used as transition enlists synecdoche as another variation on a metaphorical relationship, this one particularly apt for the fragmentation necessary to generate close-up framing. Here, the feet stand for the dancer. The next shot underscores this synecdoche by placing the dancer's body in the gallery among sculptural objects (not unlike the statuary sequence in Ritual in Transfigured Time). His depiction takes on both literal meanings (his art form mobilizes dance in an art-specific setting) and figurative ones (he serves as a figure for the art Deren is creating, metaphorically compared with the human-like art figures, and, as with the sundry states of fragmentation among the figures in the hall, he is fragmented by the camera). Multiplying the metaphorical relationships, Deren then cuts to a medium close-up of Beatty's head and shoulders, with a Bodhisattva head and shoulders also in medium close-up behind him. Beatty begins to spin, and in his spin mimics the statue behind him. Like the Bodhisattva's head, Beatty also occupies the 

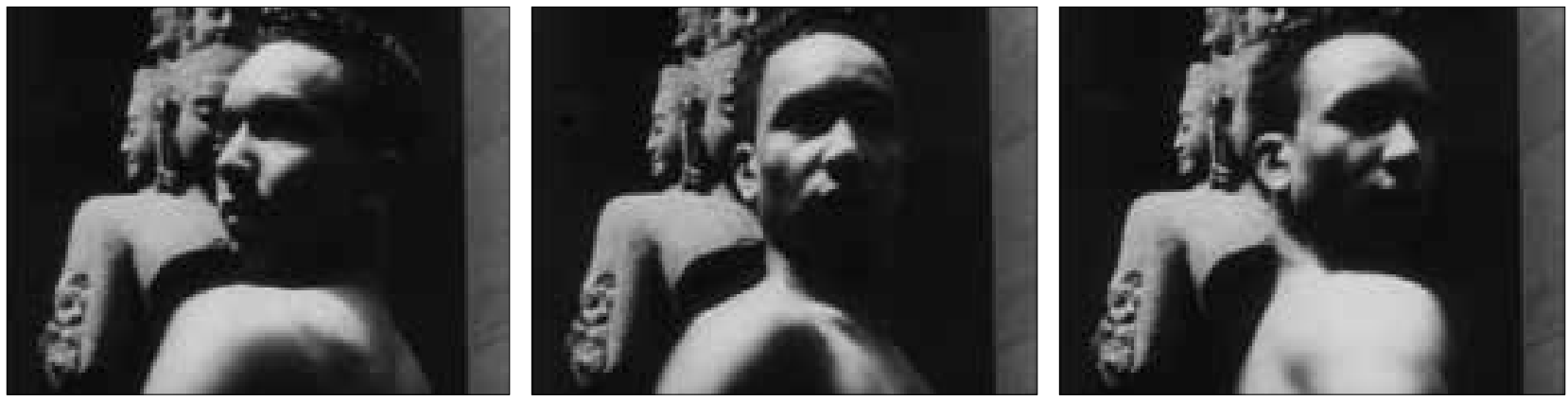

Fig. 2: The Bodhisattva Spin in A Study in Choreography for Camera (Maya Deren, 1945).

vantage point of multiple directions, especially when the spin accelerates and his head becomes blurred (Fig. 2).

P. Adams Sitney has noted that this framing brings the two figures together to evince a metaphorical relationship: "The implied metaphor identifies the dancer, whose twirling head seems to face all directions at the same time, with the statue and relates to the theme of the ambiguity of space (here, direction)." Sitney further deems the resulting metaphor a "compositional" metaphor, "one made by framing rather than by interrupting the action/ image with superimposition or intercutting."21 This type of composition is a further elaboration in Deren's multiform uses of metaphor. She doesn't underline the metaphor in the same way that cutting between the statue and Beatty's spin would: instead, the context of the shot (the museum) provides a justification for the juxtaposition; the spectator is left to piece the fragments of the shot together.

Echoing the statuary sequence in Ritual in Transfigured Time, the relative stasis of the statue-a stand-in for plastic arts more generally-draws attention to the difference cinema makes (motion), while the framing of the shot asks us to consider how the camera expresses an idea. (Deren does not intercut, but she could have: both would express something, but this is more compact.) Of course, the Bodhisattva head associates Beatty with the dancing figure Hevajra who occupies all directions and sees everywhere at once. For Beatty, too, in his spin assisted by Deren's acceleration of the motion, faces all directions at once: a modern, technologically supported, cross-medial, and artistic expression of omniscience.

The combination of Beatty's spinning movement with the camera's varying speed of movement underlines Deren's filmic practice: she employs her camera not simply to record Beatty's dance, but to expose the uniquely harmonious cinematic/terpsichorean nature of her endeavor. The way she describes this sequence in publicity materials and later articles invokes her pride in having devised the way to achieve the shot, followed by a series of metaphors that underlines how she thinks about the metaphorical qualities of this imagery more generally. Beatty is a "dervish," with the "frenzied whirling of a machine pace."22 His feet twirl him increasingly fast, "like spinning top."23 In Deren's films, the effect of the shotits overall qualities in relation to other qualities across the film, rather than its position in the linear sequence of the sections or shots_takes precedence: "... in the course of the shot, the camera speed was changed from extreme slow motion to extreme acceleration. The movement, then, begins with a dreamlike quality and ends with the blurring of a machine wheel."24 Such comparisons should remind us again of Deren's cinematic antecedents, perhaps especially Dulac's metaphors of movement in her abstract film Thèmes 
et variations, particularly in that both highlight a machine aesthetic compared metaphorically to more ancient and/or natural forms, including of course dance itself. ${ }^{25}$ The chug of machinery evoked by Deren carries Beatty over into the final section of the film, a return to the woods by way of a leap, sustained for what Deren described as "a much longer period than is humanly possible."26 In a rhythmic, four-shot sequence, it depicts dance movement complemented by cinematic movement (for example, Deren runs the leap backwards, so that Beatty appears to lift effortlessly from a pirouette into the air). This set of shots, "a pas de deux between camera and dancer,"27 as Deren put it, enables the body to surmount its usual capitulation to gravity.

Dance in Deren's films engages the unique temporal possibilities of the cinematic medium and its ability to conjure images of both an abstract and wholly realistic nature to create a new cinematic reality. It does so by engaging with Deren's thinking about poetry and rhythm on a direct level: the temporality of the film is recursive rather than linear, and the images are composed with a mind to expose how such images might come into being in the cinema. Those images are set in deliberate rhythm not only by the dancer's movements before the camera, but through the camera's engagement and interaction with those movements. By the three-way merger of her sense of poetic, terpsichorean, and cinematic devices, she prompts a cross-medial investigation of ideas elevated by connections that drive her creative practice.

\section{Notes}

1. Elinor Cleghorn has posited a connection between Deren's choreographic aesthetic and her unfinished project from the same time, Witch's Cradle, as well. "Manus Operandi: Film, Sculpture, Choreography." The International Journal of Screendance 2 (Spring 2012): 129-139.

2. Deren, "Program Notes."

3. Rosenberg, 35.

4. Ibid., 42.

5. Ibid., 42-47.

6. For an elegant, cogent, historically-invested, discussion that further situates these predecessors in relation to Deren's work, see Erin Brannigan's Dancefilm: Choreography and the Moving Image. Note, too, that Deren acknowledges her interest in her predecessors in dance film if not quite her sense of their influence in reference to the earlier cinematic avant-garde in France in her Anagram of Ideas on Film, Form, and Art.

7. The dancers affiliated with the Judson Church (in Greenwich Village, New York City), where they practiced and performed, tended to make dance out of everyday movements, so that the gesture of walking, for example, would elicit a dance-like rhythm.

8. This action places Deren in the camp of media-specific theoreticians of cinema, where the properties that are deemed unique for a particular medium are mobilized and highlighted to create art.

9. Deren, Anagram.

10. The editors of The Legend of Maya Deren, Vol. I, Part 2: Chambers draw this parallel in their section "The Making of At Land." See Clark et al., 186.

11. Quoted in The Legend of Maya Deren, Vol. I, Part 1: Signatures, 347.

12. Legend of Maya Deren, Voll, Part 2, 186-87.

13. Hammid quoted in Legend of Maya Deren, Vol I, Part 2, from interviews conducted on September 4, 1975 and August 3, 1976. Deren continued to write poetry even after she begins to identify as a filmmaker, though less often than before.

14. For a detailed account of Deren's ideas as expressed in the symposium, see the reprint of part of the transcript of that event, "Poetry and the Film," 171-186. 
15. Pound, 3.

16. Legend I.2, 57.

17. Brakhage, 13.

18. This sequence was filmed in the Egyptian wing of the Metropolitan Museum of Art, New York.

19. Deren describes the genesis of this shot in her article for Dance in 1945. Essential Deren: 222-223.

20. Ibid., 223.

21. Sitney, "Imagism," 188. Sitney takes the term "compositional" metaphor from Eisenstein; see for example "Laocoön."

22. Deren, "Original Plan for A Study in Choreography for Camera."

23. Ibid.

24. Ibid. A very similar formulation occurs in "Choreography for the Camera," op cit., 223.

25. The relationship of machinery and modernism to both mainstream and avant-garde film practices, particularly as it expresses cinematic rhythm (the cinema of course being itself a machine), has been explicated in several recent works, including Kristin Whissel's Picturing American Modernity: Traffic, Technology and the Silent Cinema, Lucy Fischer's recent work presented for the Philadelphia Cinema and Media Seminar in April, 2012, "Modernity, Machine, Movies, Mind: Abel Gance's La Roue," and Tom Gunning's essay on Chaplin, "Chaplin and the Body of Modernity," a talk given at the BFI international conference on Chaplin on 22 July 2005. The proceedings of the entire conference are available on the BFI website: http://chaplin.bfi.org.uk/programme/conference/ papers.html

26. Deren, "Choreography for the Camera," 224.

27. Deren, "Program Notes.

\section{References}

Brakhage, Stan. Film at Wit's End: Eight Avant-Garde Filmmakers. New York: McPherson \& Co., 1989.

Brannigan, Erin. Dancefilm: Choreography and the Moving Image. New York: Oxford University Press, 2011.

Clark, VèVè, Millicent Hodson, and Catrina Neiman. The Legend of Maya Deren, Vol. I, Part 1: Signatures (Legend, I.1). New York: Anthology Film Archives, 1988.

.The Legend of Maya Deren, Vol. I, Part 2: Chambers (Legend, I.2). New York: Anthology Film Archives, 1976.

Cleghorn, Elinor. "Manus Operandi: Film, Sculpture, Choreography." The International Journal of Screendance 2 (Spring 2012): 129-139.

Deren, Maya. An Anagram of Ideas on Art, Form, and Film. In Maya Deren and the American Avant-Garde, edited by Bill Nichols, 267-322. Berkeley: Univ. of California Press, 2001.

. "Original Plan for A Study in Choreography for Camera." Maya Deren Collection (MDC), Howard Gotlieb Archival Research Center, Boston University Library.

. "Program notes." February, 1946. MDC.

Eisenstein, Sergei. "Laocoön." In Selected Works, Vol. II., edited by Michael Glenny and Richard Taylor, 109-202. London: I.B. Tauris, 2010.

Fischer, Lucy. "Modernity, Machine, Movies, Mind: Abel Gance's La Roue." Lecture for the Philadelphia Cinema and Media Seminar, April, 11 2012. Fisher-Bennett Hall, University of Pennsylvania.

Gunning, Tom. "Chaplin and the Body of Modernity." Lecture for the BFI international conference on Chaplin, 22 July 2005. Available: http://chaplin.bfi.org.uk/programme/conference/papers.html

"Poetry and the Film: A Symposium with Maya Deren, Arthur Miller, Dylan Thomas, Parker Tyler. Chairman, Willard Maas. Organized by Amos Vogel." Film Culture Reader, P. Adams Sitney, editor. New York: Cooper Square Press, 2000.

Pound, Ezra. "A Retrospect." In Literary Essays of Ezra Pound, edited by T.S. Eliot, 3-14. London: Faber \& Faber, 1954. Rosenberg, Douglas. Screendance: Inscribing the Ephemeral Image. New York: Oxford University Press, 2012.

Sitney, P. Adams. "Imagism in Four Avant-Garde Films." In Film Culture Reader, 195-199. New York: Cooper Square Press, 2000.

Whissel, Kristen. Picturing American Modernity: Traffic, Technology and the Silent Cinema. Durham, NC: Duke University Press, 2008. 